\title{
Low Grade Myofibroblastic Sarcoma of the Tongue: A Case Report in an Infant
}

\section{Sylvain Diembi ${ }^{1}$, Donatien Moukassa ${ }^{2,3^{*}}$, Franck Arnaud Itiéré Odzili ${ }^{4}$, Chidrel Gérard Ngouoni ${ }^{4}$, Boris Otouana Dzon4, Gontran Ondzotto ${ }^{4}$}

\author{
${ }^{1}$ Service d'ORL et de chirurgie cervico-faciale, HGAS, Pointe Noire, Congo \\ ${ }^{2}$ Département des masters, Faculté des Sciences de la Santé, UMNG, Brazzaville, Congo \\ ${ }^{3}$ Laboratoire d'Analyses Médicales et Morphologiques, HGL, Pointe Noire, Congo \\ ${ }^{4}$ Service d'ORL et de chirurgie cervico-faciale, CHU, Brazzaville, Congo \\ Email: *donatienmoukassa@gmail.com
}

How to cite this paper: Diembi, S., Moukassa, D., Itiere Odzili, F.A., Ngouoni, C.G., Dzon, B.O. and Ondzotto, G. (2018) Low Grade Myofibroblastic Sarcoma of the Tongue: A Case Report in an Infant. Open Journal of Pathology, 8, 24-30.

https://doi.org/10.4236/ojpathology.2018.8 $\underline{1003}$

Received: December 11, 2017

Accepted: January 8, 2018

Published: January 11, 2018

Copyright (C) 2018 by authors and Scientific Research Publishing Inc. This work is licensed under the Creative Commons Attribution International License (CC BY 4.0).

http://creativecommons.org/licenses/by/4.0/

\begin{abstract}
A case of a 12-month-old male infant, who presented a painless swelling of the right anterolateral edge of the mobile tongue, is reported. The treatment consisted of a partial glossectomy with total surgical excision of the tumor. The diagnosis of low grade myofibroblastic sarcoma on the histological arguments (tumor architecture, cytology, mitotic index) and immunohistochemistry was retained.
\end{abstract}

\section{Keywords}

Soft Tissue Sarcomas, Histological Variety, Myofibroblastic Sarcoma, Infant Tongue

\section{Introduction}

Soft tissue sarcomas (STS) account for less than 1\% of all adult cancers, and about 15\% of child cancers [1] [2]. Their morphologic features and clinical time course are often heterogeneous, which makes them difficult to diagnose and treat.

According to the histological classification of the WHO of soft tissue tumors (2013) [2] and taking into account morphological data reported by CD Fletcher et al. [3], T. Mentzel et al. in 1998 [4], myofibroblastic sarcoma is classified in the group of fibroblastic and myofibroblastic tumors developed from soft tissues. Considering their histological differentiation and time course, severity of myofibroblastic sarcoma is ranked as low, intermediate or high grade. The last two histoprognosis varieties (intermediate and high grade) may relapse locally and 
give distant metastases [5].

STS with a low degree of malignancy often localize (30\% of cases) at the head and neck, including the mouth, tongue, face, neck and bones of the face (upper maxillary bone, mandible). However, such tumors can occur in deep soft tissues elsewhere. It represents a rare histological variety, especially when it develops at unusual sites, and furthermore in an infant [5].

We report here the case of a lingual myofibroblastic sarcoma in a 12-month-old infant. This case occurring in a context of limited resources poses a triple problem regarding diagnosis, prognosis and treatment.

\section{Case Report}

The 12-month-old male infant was admitted to the Otorhinolaryngology (ORL) department at the Adolphe Sicé General Hospital at Pointe-Noire (Congo) in December 2014, for a painless swelling of the right anterolateral edge of the mobile tongue. The anomaly had appeared four months after birth. The child had no other medical or surgical history and was born after a term pregnancy without any significant incident.

The parents, having discovered a small nodule located on the right free edge of the tongue, had taken the child to the hospital for an ORL medical consultation. The child's general condition was satisfactory. The medical examination revealed a painless nodule, well circumscribed, measuring $1.5 \mathrm{~cm}$ long axis, and extending from the dorsal to the ventral side of the tongue (Figure 1). The search for superficial or deep lymphadenopathy invasion was negative (chest X-ray and thoracoabdominal ultrasound scan). Partial glossectomy with total surgical excision of the tumor was decided and performed.

Two years later (November 23, 2016), a tumor recurrence appeared at the primary sampling site. A new and larger resection was performed, with a satisfactory

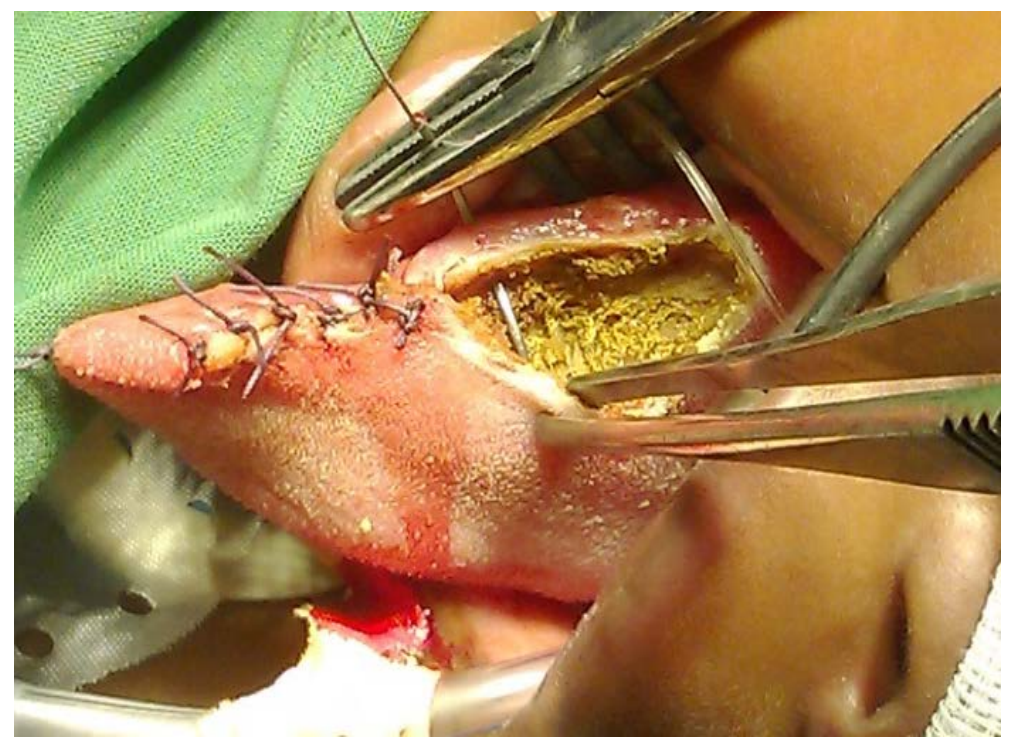

Figure 1. Site of partial glossectomy anterolateral right. 
histopathological analysis of the resection edges. Nowadays, the child is still under clinical surveillance.

The surgical specimen from partial glossectomy was hand-sliced. The macroscopic examination of the slices showed a homogeneous, pale nodule without any necrotic or calcified patches (Figure 2).

After paraffin inclusion of the specimen, 5- to 6- $\mu \mathrm{m}$ slices were stained with hematoxylin eosin saffron (HES) and examined microscopically. The lingual mucosa was coated with a squamous epithelium limited by a rectilinear and regular basement membrane. The underlying connective tissue was the seat of the tumor proliferation made of fusiform cells arranged in bundles of variable length, sometimes realizing storiform structures (Figure 3 and Figure 4). Tumor cells appeared

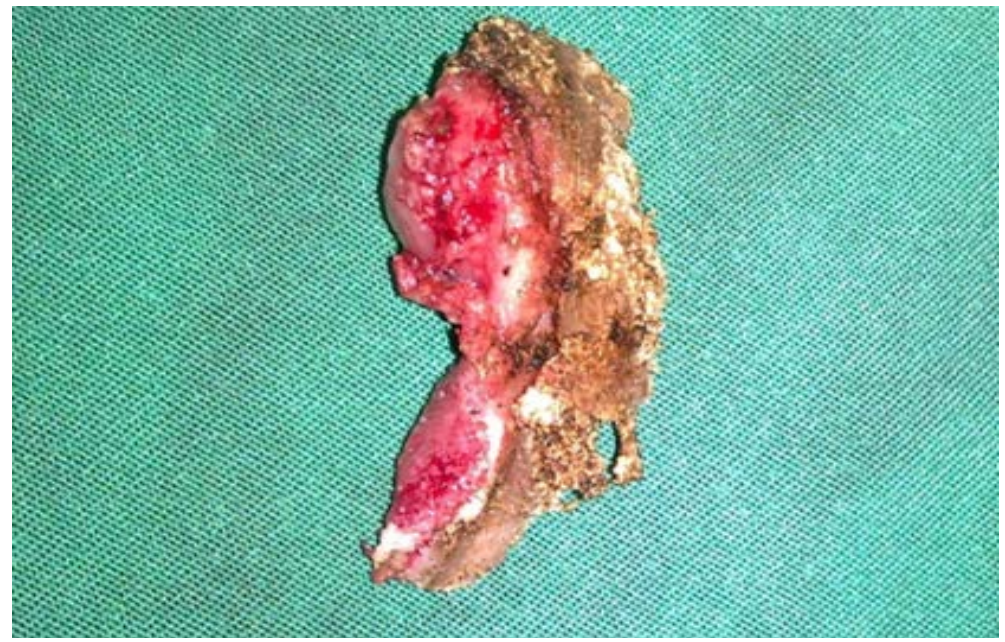

Figure 2. Partial glossectomy piece of $2 \mathrm{~cm}$, comprising a tumor of $1.5 \mathrm{~cm}$ in major axis.

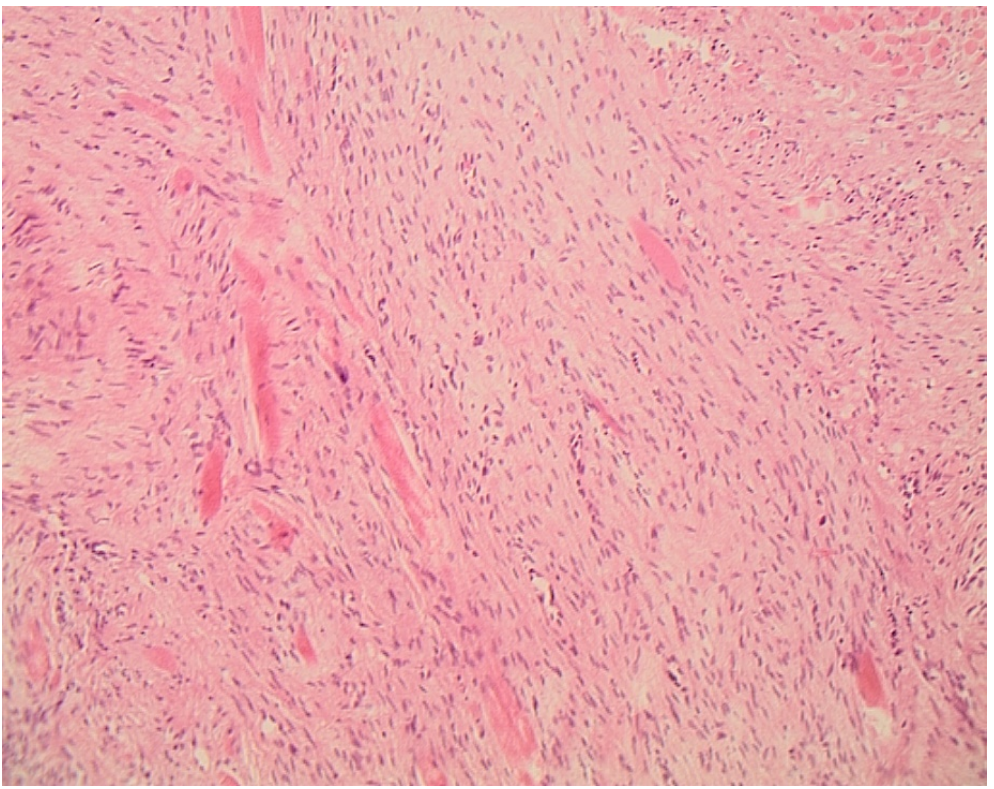

Figure 3. Proliferation of fusiform and storiform cells HES GX40. 


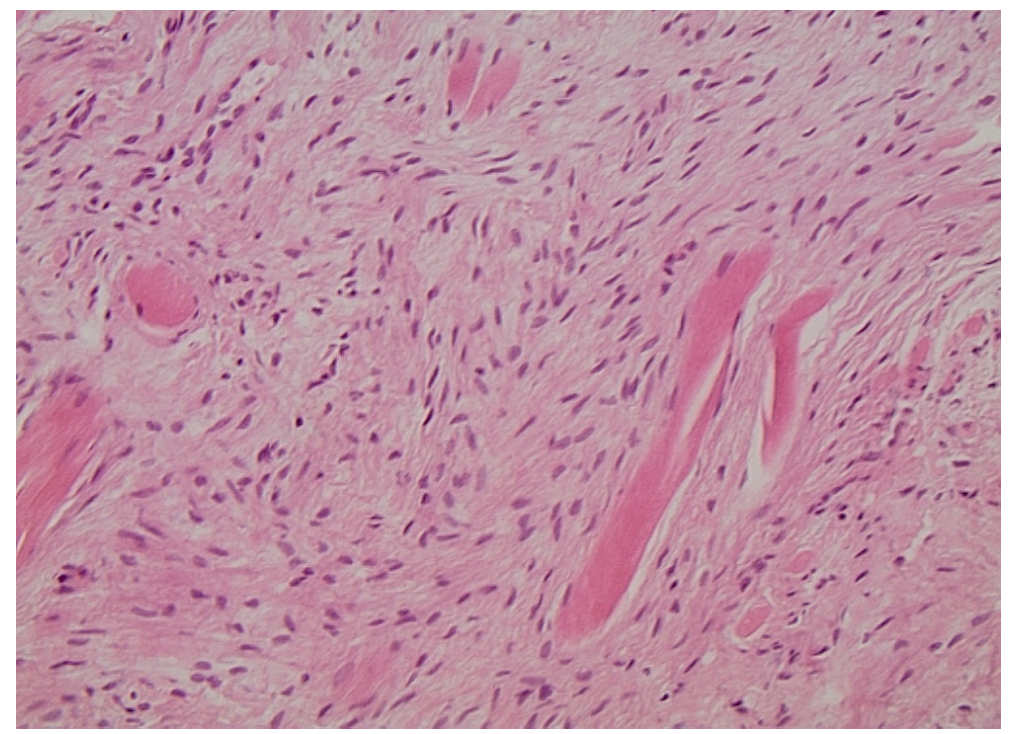

Figure 4. Proliferation of fusiform cells dissociating striated muscle fibers. HES GX60.

with eosinophilic cytoplasm, finely fibrillar, abundant and poorly limited. The nuclei were tapered, with pointed ends, fine chromatin, and weak cyto-nuclear atypia. The mitotic index equaled 1 to 2 mitoses per 10 fields at high magnification $(\times 40)$ for a $0.62 \mathrm{~mm}$ microscopic field diameter. The tumor stroma was thin and non-inflammatory. This fusocellular proliferation unevenly dissociated the underlying striated muscle fibers, and came into contact with the deep excisional bank. There were no plaques of necrosis or bleeding.

Immunohistochemically, tumor cells expressed smooth muscle actin (Figure 5), desmin (Figure 6), and caldesmon in the form of intense, diffuse cytoplasmic staining. Anti-myogenin antibody treatment revealed a low positivity with focal cytoplasmic staining. Anti-AE1/AE3 (pancytokeratin), anti-epithelial membrane antigen (EMA), anti-protein S100 (PS100), and anti-CD34 antibodies applications were negative, and eliminated an epithelial, nerve or vascular origin of cell proliferation. The bidirectional sequencing search for the somatic mutation of the exon of MYOD1 was negative.

We were faced with this fusocellular proliferation of myofibroblastic origin developed at the level of the right anteroposterior edge of the free tongue, and with the difficulty to determine the histological type of the tumor. We therefore requested an expert diagnostic opinion [Pr. J.M. Coindre (France), Dr. C. Fletcher (USA)]. The diagnosis of low grade myofibroblastic sarcoma was retained on the histological (tumor architecture, cytology, mitotic index) and immunohistochemical arguments

\section{Discussion}

According to most data reported in the literature, low-grade myofibroblastic sarcomas [5] [6] are more likely to affect middle-aged patients by the age of 50, 


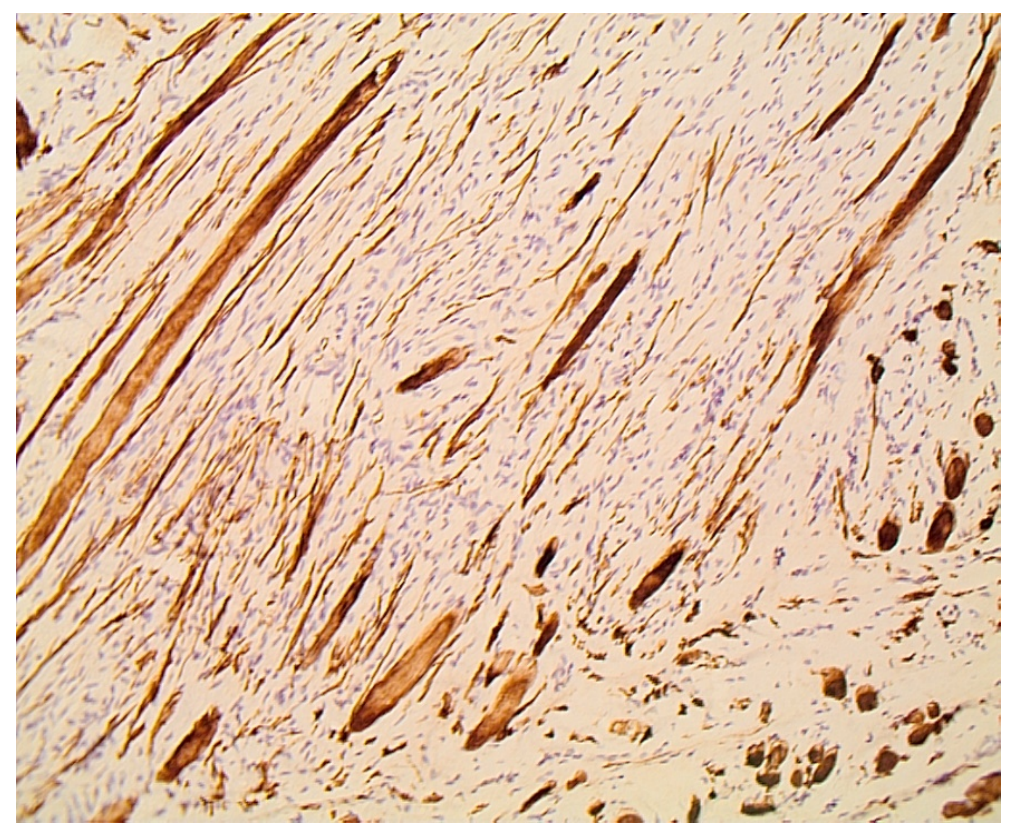

Figure 5. Immunohistochemistry. Tumor cells expressed smooth muscle actin (SMA). GX40.

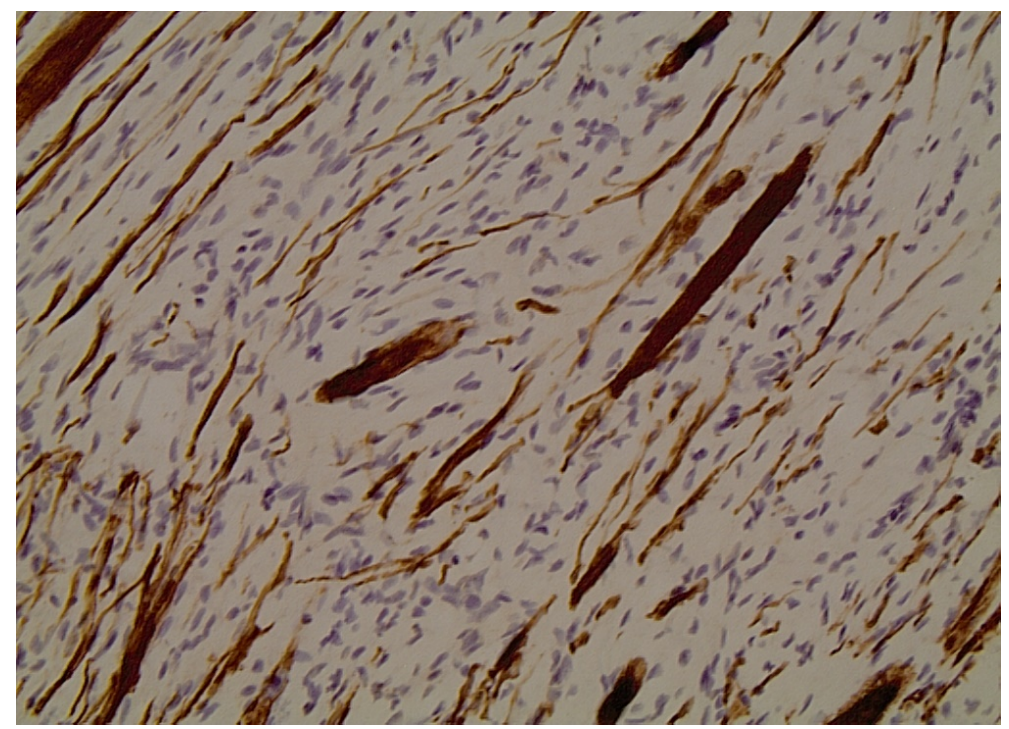

Figure 6. Immunohistochemistry. Tumor cells expressed desmin. GX60.

with no gender predominance. The condition appears often in the form of a painless slowly growing nodule. These tumors are of good prognosis, they recur in $1 / 3$ of the cases and the metastases are rare ( $<7 \%$ of the cases), and appear most often in the lungs [6]

The positive diagnosis and histoprognostic grade of myofibroblastic sarcoma are determined through histological and immunohistochemical examination. Analysis of the tumor tissue by electron microscopy allows to highlight the myofibroblastic differentiation, which is defined by the presence of an abundant granular endoplasmic reticulum, bundles of actin microfilaments located under 
the plasma membrane, and associated with the presence of dense bodies called fibronexus or microtendon [5] [7] [8]. However, the diagnosis is difficult and based on the basis of morphological architecture and the expression of myofibroblastic profile antigens, such as smooth muscle actin, desmin, caldesmon and myogenin. The differential diagnosis is established microscopically with nodular fasciitis and inflammatory myofibroblastic tumor [9]. Multidisciplinary meeting and medical expertise consultation are often the only consensual way of definitively retaining the diagnosis [10]. In the present case, the development of such a tumor in a 12-month-old infant in a context of limited resources, was even more difficult to document.

Surgical excision of the tumor is the treatment of choice. Some authors advise to associate radiotherapy in case of incomplete surgical excision or in the case of inaccessible location for surgery [6]. In our case, the infant had an easily accessible lingual location for simple excision. The initial excision was insufficient; a surgical revision was performed with regard to the analysis of intratumoral exeresis edges. The complementary microscopic examination of the second excision specimen showed healthy surgical margins.

Because of the low histoprognostic grade of this myofibroblastic sarcoma with low metastatic potential, it was decided to perform regular and prolonged surveillance after the complementary surgical excision. Three years later, there was no evidence of tumor recurrence or metastasis.

\section{Conclusion}

We report the case of a lingual localization myofibroblastic sarcoma, in a 12-month-old infant who poses the triple problem of diagnosis, prognosis and treatment in a context of limited resources.

\section{Acknowledgements}

The authors thank Dr. Christopher Fletcher and Professor Jean Michel Coindre for their expert advice, and Professor Alain Buguet for his contributions in the proofreading of the manuscript.

\section{Conflict of Interest}

The authors declare that they have no conflict of interest.

\section{References}

[1] Fletcher, C.D., Bridge, J., Hogendoorn, P. and Mertens, F. (2013) WHO Classification of Tumours of Soft Tissue and Bone. 4th Edition, IARC Press, Lyon, 15-18.

[2] Vickie, Y., Jo, C. and Fletcher, D.M. (2014) WHO Classification of Soft Tissue Tumours: An Update Based on the 2013 (4th) Edition. Pathology, 46, 95-104. https://doi.org/10.1097/PAT.0000000000000050

[3] Fletcher, C.D. (1998) Myofibroblastic Tumours: An Update. Verh Dtsch Ges Pathol, 82, 75-82.

[4] Mentzel, T., Dry, S., Katenkamp, D. and Fletcher, C.D. (1998) Low-Grade Myofi- 
broblastic Sarcoma: Analysis of 18 Cases in the Spectrum of Myofibroblastic Tumors. American Journal of Surgical Pathology, 22, 1228-1238.

https://doi.org/10.1097/00000478-199810000-00008

[5] Montgomery, E., Goldblum, J.R. and Fisher, C. (2001) Myofibroblastic Sarcoma: A Clinicopathologic Study. American Journal of Surgical Pathology, 28, 219-228.

https://doi.org/10.1097/00000478-200102000-00010

[6] Alno, N., de Mello, G., Clipet, F., Roudi, P., Lombardi, T. and Samson, J. (2008) Sarcome myofibroblastique de bas grade: Encore un cas sur la langue. Médecine Buccale Chirurgie Buccale, 14, 239-244. https://doi.org/10.1051/mbcb/2008006

[7] Neuville, A., Chibon, F. and Coindre, J.M. (2014) Grading of Soft Tissue Sarcomas: From Histological to Molecular Assessment. Pathology, 46, 113-120. https://doi.org/10.1097/PAT.0000000000000048

[8] Takácsi-Nagy, Z., Muraközy, G., Pogány, P., Fodor, J. and Orosz, Z. (2009) Myofibroblastic Sarcoma of the Base of Tongue. Case Report and Review of the Literature. Strahlentherapie und Onkologie, 185, 198-201.

https://doi.org/10.1007/s00066-009-1925-8

[9] Mentzel, T. (2001) Myofibroblastic Sarcomas: A Brief Review of Sarcomas Showing a Myofibroblastic Line of Differentiation and Discussion of the Differential Diagnosis. Current Diagnostic Pathology, 7, 17-24. https://doi.org/10.1054/cdip.2000.0057

[10] Chan, J.Y., Gooi, Z., Wong, E.W., Ng, S.K., Tong, M.C. and Vlantis, A.C. (2017) Low-Grade Myofibroblastic Sarcoma: A Population-Based Study. Laryngoscope, 127, 116-121. https://doi.org/10.1002/lary.26146 